\title{
Colonization by Cupriavidus taiwanensis KKU2500-3 Enhances the Growth and Yield of KDML105 Jasmine Rice
}

\author{
Putthita PUNJEE ${ }^{1}$, Wilailak SIRIPORNADULSIL ${ }^{1,2,4}$ and \\ Surasak SIRIPORNADULSIL ${ }^{1,2,3, *}$
}

\author{
${ }^{1}$ Department of Microbiology, Faculty of Science, Khon Kaen University, Khon Kaen 40002, Thailand \\ ${ }^{2}$ Research Center for Environmental and Hazardous Substance Management, Khon Kaen University, \\ Khon Kaen 40002, Thailand \\ ${ }^{3}$ Salt-Tolerant Rice Research Group, Khon Kaen University, Khon Kaen 40002, Thailand \\ ${ }^{4}$ Center for Alternative Energy Research and Development, Khon Kaen University, \\ Khon Kaen 40002, Thailand
}

('Corresponding author's e-mail: surasak@kku.ac.th)

Received: 13 September 2017, Revised: 31 January 2018, Accepted: 19 February 2018

\begin{abstract}
The effects of the cadmium-tolerant bacterium Cupriavidus taiwanensis KKU2500-3 on the growth and grain production of jasmine rice (Oryza sativa L. var. KDML105) were studied. Bacterial cells were inoculated onto rice seedlings before transplanting into a hydroponic system; the cells successfully colonized, became distributed, and multiplied in the range of $10^{4}-10^{9} \log \mathrm{CFU} \cdot \mathrm{g}^{-1}$ plant. The bacterial cells were localized to the cell wall and the intercellular space of all plant parts. Moreover, inoculation of strain KKU2500-3 significantly promoted rice growth by increasing the length, dry mass of shoots and roots, and chlorophyll concentration in leaves, and improved yields by increasing the panicle length, number of seeds/panicle, number of filled grains/panicle, filled grain percentage, and 100-grain weight (13.57, 11.90, 48.20, 32.55, and 23.53\% over the control, respectively). The number of filled grains/panicle and grain weight accounted for the increase in total yield. C. taiwanensis KKU2500-3 fixed nitrogen, produced indole-3-acetic acid, and solubilized phosphate, affecting the growth and yield of all plants. Successful colonization of rice seedlings before transplanting is an important finding, as it will simplify bacterial inoculation of plants, especially when grown in cadmium-contaminated rice fields.
\end{abstract}

Keywords: Cupriavidus taiwanensis KKU2500-3, KDML105 jasmine rice, colonization, hydroponic system

\section{Introduction}

Rice is considered to be one of the most essential staple foods of humans. With the rapid growth in the worldwide population, the amount of rice needed has increased dramatically, and enhancing productivity per unit of land area is a major goal for meeting the increasing demand for this crop. Such increases in production can be achieved by optimizing agricultural practices, such as nitrogen fertilization, by improving technologies to produce higher yields at a lower cost, and in a worsening environment, and by ensuring food security. Overall, it is necessary to apply innovative approaches, such as genetic methods and the use of exogenous plant growth regulators, to increase rice production. Within this context, numerous researchers have shown that many rice cultivars differ with regard to their growth, grain yield, yield components, and quality.

Thai jasmine rice, or Khao Dawk Mali 105 (Oryza sativa L. var. KDML105), is the most popular among Thai rice species. It is traditionally grown in the northern and northeastern regions of Thailand for 
export. Because it has a good cooking quality, and is aromatic and supple, many farmers have been encouraged to plant this variety. Unfortunately, planting rice in an unsuitable area, especially in a drought or inundation area, results in low yield and quality, as well as instability. Moreover, some regions have been affected by environmental problems, for example, heavy metal contamination and the use of agricultural chemicals, such as herbicides, pesticides, or chemical fertilizers, which cause soil deterioration. These factors have direct effects on rice production. For these reasons, a major goal of this study is to increase productivity as much as possible in a restricted area, while reducing the use of chemical fertilizers.

Several studies have reported that the plant growth-promoting activities of various microorganisms can improve crop growth and yield, and such growth promotion is especially true for plant growthpromoting rhizobacteria (PGPR), which are distributed in the rhizosphere or colonized in roots. These microbes possess advantageous mechanisms to encourage plant growth in various ways, including the ability to generate indole-3-acetic acid (IAA) [1,2], ammonia $\left(\mathrm{NH}_{3}\right)$, hydrogen cyanide (HCN), siderophores, soluble phosphate, and antifungal agents [1]. Some microbes of the genus Cupriavidus have been found in association with the rhizospheres of various plants. In particular, C. taiwanensis LMG 19424, which was first discovered in Taiwan, was found to colonize the root nodule of Mimosa pudica [3], as well as many Mimosa species around the world [4]. This bacterium is considered to be among the rhizobia that cooperate with legumes in mutualistic endosymbiosis and induce the development of root nodules for nitrogen fixation, providing nitrogen to the host plant.

C. taiwanensis strain KKU2500-3 was not isolated directly from a plant but, instead, from cadmiumcontaminated soils of paddy fields in Mae Sot District, Tak Province, Thailand. KKU2500-3 was able to improve rice seedling growth in the presence of $200 \mathrm{mM} \mathrm{CdCl}_{2}$, and the plants also produced the greatest number of fibrous roots [5]. KKU2500-3 was observed to colonize root surfaces, becoming distributed and multiplying in the roots and shoots of rice plants. The plants also exhibited enhanced growth in a medium lacking nitrogen, with increased chlorophyll content ( $~ 8$ times) when cultured in the presence of $\mathrm{CdCl}_{2}[6,7]$. Due to varying environmental factors and field conditions, including weather, soil properties, and the diversity or activity of native microorganisms in the host and soil, interactions between microbes and plants may be unstable. Therefore, it is necessary to develop rice plants that grow efficiently under greenhouse conditions in a hydroponic system, and possible approaches include exploring plant growthpromoting activities and plant adaptation to particular microbial communities. Accordingly, this study aimed to clarify the effects of C. taiwanensis KKU2500-3 on rice growth and yield and to elucidate various plant growth-promoting activities. The findings of this study may provide an efficient method to promote plant productivity through bioinoculants, which may have potential use as biofertilizers in the field, especially in cadmium-contaminated soils.

\section{Materials and methods}

\section{Materials}

Seeds of KDML105 jasmine rice were kindly provided by the Khon Kaen Rice Research Center, Thailand. C. taiwanensis KKU2500-3 was isolated from a cadmium-contaminated paddy field in the Mae Sot District of Tak Province [5].

\section{Bacterial growth in $\mathbf{N}$-free and $\mathbf{N}$-enrich medium}

The growth of $C$. taiwanensis KKU2500-3 was evaluated in Burk's N-free medium or nutrient broth (NB), a nitrogen-rich medium, at $30^{\circ} \mathrm{C}$ and $150 \mathrm{rpm}$. Bacterial growth was observed at 6-hr intervals until reaching stationary phase. The growth curves of the bacterial strain cultured in both media were then compared.

\section{IAA production assay}

The ability of the bacteria to synthesize IAA was examined via IAA quantification using a modified method of Bric et al. [9]. C. taiwanensis KKU2500-3 was grown in NB supplemented with 0, 50, 150, 300,400 , or $500 \mu \mathrm{M} \cdot \mathrm{mL}^{-1}$ tryptophan for $24 \mathrm{~h}$ at $30{ }^{\circ} \mathrm{C}$ and $120 \mathrm{rpm}$. The cells were separated by 
http://wjst.wu.ac.th

centrifugation for $15 \mathrm{~min}$ at $4{ }^{\circ} \mathrm{C}$ and $6,000 \mathrm{rpm}$. Orthophosphoric acid solution (2 drops) and Salkowski reagent $(4 \mathrm{~mL})$ were added to the supernatant $(2 \mathrm{~mL})$. The reaction was kept at room temperature until a pink color developed, and the amount of IAA in the solution was quantified by spectrophotometry at 530 $\mathrm{nm}[1]$.

\section{Siderophore production assay}

The ability of the bacteria to synthesize siderophores was determined by growing C. taiwanensis KKU2500-3 in NB at $30{ }^{\circ} \mathrm{C}$ and $120 \mathrm{rpm}$ until reaching the mid-log phase (approximately 18 to $19 \mathrm{~h}$ ). We dripped $10 \mu \mathrm{L}$ of a cell suspension at a concentration of $10^{6} \mathrm{CFU} \cdot \mathrm{mL}^{-1}$ onto chrome azurol $\mathrm{S}$ agar medium, and allowed the bacteria to grow at $30{ }^{\circ} \mathrm{C}$ for $48-72 \mathrm{~h}$. The appearance of an orange color surrounding the colonies indicates siderophore production $[1,10]$.

\section{Phosphate solubilization assay}

The phosphate solubilization capacity of the bacteria was assessed by growing C. taiwanensis KKU2500-3 on Pikovskaya's medium at $30{ }^{\circ} \mathrm{C}$ for $48-72 \mathrm{~h}$. A clear zone surrounding the colony indicates the ability to dissolve phosphate $[11,12]$. The amount of tricalcium phosphate solubilized by $C$. taiwanensis KKU2500-3 was measured using the method of King [13] by growing the cells in Pikovskaya's broth at $30{ }^{\circ} \mathrm{C}$ for $96 \mathrm{~h}$. The broth was then centrifuged at $4{ }^{\circ} \mathrm{C}$ and $15,000 \mathrm{rpm}$ for 30 min to collect the supernatant, which was combined with chloromolybdic acid solution $(1 \mathrm{~mL})$ and distilled water $(10 \mathrm{~mL})$ to yield approximately $45 \mathrm{~mL}$. Chlorostannous acid $(0.25 \mathrm{~mL})$ was then added to the mixture, followed by distilled water to reach $50 \mathrm{~mL}$ of the total amount, before incubating at room temperature to generate a blue color. The concentration of solubilized phosphate in the solution was measured at $600 \mathrm{~nm}$ and quantified by comparison to a standard curve of $\mathrm{KH}_{2} \mathrm{PO}_{4}$.

\section{Rice growth under phosphate-free and phosphate-enriched conditions}

The KDML105 jasmine rice seeds were surface sterilized with $90 \%$ ethanol for $3 \mathrm{~min}$, followed by an incubation with $0.2 \%$ mercuric chloride for $30 \mathrm{~min}$. Next, the seeds were washed 3 times with sterile distilled water and then stored in the dark for germination. Three days after germination $(0.5 \mathrm{~mm}$-longroots), the seedlings were separated into 2 sets. For the first set, $5 \mathrm{ml}$ of a bacterial suspension $\left(5 \times 10^{6}\right.$ $\mathrm{CFU} \cdot \mathrm{mL}^{-1}$ in normal saline) was added to generate bacterial-colonized rice plants (RB), and the same amount of normal saline was added to the second set to generate non-bacterial colonized rice plants (R), with both sets maintained in the dark for 2 days. Afterwards, the seedlings were transferred to grow in Hoagland's agar, prepared from a combination of $0,10,20,50$, and $100 \%$ soluble phosphate $\left(\mathrm{KH}_{2} \mathrm{PO}_{4}\right.$ $0.0068 \mathrm{~g} / 100 \mathrm{ml})$ and $100,90,80,50$, and $0 \%$ insoluble phosphate $\left(\mathrm{CaHPO}_{4} \cdot 2 \mathrm{H}_{2} \mathrm{O}\right)$, respectively. The experiments were performed under controlled conditions in a growth chamber with $70 \%$ relative humidity and a $14: 10 \mathrm{~h}$ light-dark cycle at a light intensity of $1,000 \mu \mathrm{mol} \mathrm{m} \mathrm{s}^{-2}$ for 9 days at $25{ }^{\circ} \mathrm{C}$. Next, the rice samples ( 3 plants/replicate, 3 replicates/treatment) were randomly collected to assess growth by measuring shoot and root length and dry weight.

\section{Colonization of $C$. taiwanensis KKU2500-3 in rice}

The seeds of KDML105 jasmine rice were surface sterilized with $90 \%$ ethanol for 3 min, followed by incubation with $0.2 \%$ mercuric chloride for $30 \mathrm{~min}$, after which the seeds were washed 3 times with sterile distilled water. The sterile seeds were grown on sterile $0.1 \%$ tryptic soya agar [14] for 3 days. Sterile seedlings (without bacterial colonies on or around the agar) were selected and transplanted onto a semisolid solution of Hoagland and Arnon [15] in sterile bottles. The experiments were performed under controllable conditions in a growth chamber: $70 \%$ relative humidity and 16:8 h light-dark cycle at a light intensity of $1,000 \mu \mathrm{mol} \mathrm{m} \mathrm{s}^{-1}$ for 3 days after transplanting (DAT) at $28^{\circ} \mathrm{C}$. Bacterial cells were prepared by culturing in $\mathrm{NB}$ at $30{ }^{\circ} \mathrm{C}$ and $150 \mathrm{rpm}$ in a rotating incubator for $18-19$ to obtain cells in mid-log phase. The bacterial suspension was centrifuged, and the pellet was double washed with sterile saline before being resuspended in phosphate-buffered saline (PBS). At 3 DAT, the rice seedlings were 
http://wjst.wu.ac.th

separated into 2 sets for continuous growth for another 15 days in a growth chamber, including a set inoculated with $5 \times 10^{6}$ cells $\cdot \mathrm{mL}^{-1}$ of $C$. taiwanensis $\mathrm{KKU} 2500-3$ and an uninoculated control set.

\section{Transplantation of rice into the hydroponic system and treatments}

The 2 sets of seedlings at 15 DAT were separated into 2 groups (R and $R B$ ) that were grown separately in a hydroponic system containing Hoagland's solution.

\section{Bacterial colonization assessments}

Inoculated rice seedlings were collected ( 3 plants/replicate, 3 replicates/treatment) once per month and separated into 3 parts to assess colonization, including the roots, the shoot base, and the leaves. For bacterial colonization on the root exterior, roots were excised, washed to remove loosely associated bacteria, and then shaken vigorously in sterile saline for $30 \mathrm{~s}$ to detach rhizosphere bacteria. The suspension was diluted with sterile saline (10-fold series) and spread onto nutrient agar containing 500 $\mu \mathrm{M} \mathrm{CdCl}$, which can be used to specifically select for strain KKU2500-3 [5]. The rice-colonizing bacteria expected to be $C$. taiwanensis KKU2500-3 were counted in CFU $\cdot \mathrm{g}^{-1}$ plant and identified by $16 \mathrm{~S}$ rDNA analysis. Bacterial colonization in the interior of the plants was assessed by separately grinding followed by 10 -fold serial dilution of roots and shoots in sterile saline. Each dilution was then spread onto nutrient agar containing $500 \mu \mathrm{M} \mathrm{CdCl}_{2}$. The cadmium-tolerant bacteria that colonized the plants and were expected to be $C$. taiwanensis $\mathrm{KKU} 2500-3$ were counted in $\mathrm{CFU} \cdot \mathrm{g}^{-1}$ plant and identified by $16 \mathrm{~S}$ rDNA analysis.

\section{Bacterial identification by $16 S$ rDNA}

A 16S rDNA-based polymerase chain reaction (PCR) technique was performed using optimized conditions (pre-denaturation, $94{ }^{\circ} \mathrm{C} / 3 \mathrm{~min}$; denaturation, $94{ }^{\circ} \mathrm{C} / 30 \mathrm{~s}$; annealing, $66{ }^{\circ} \mathrm{C} / 30 \mathrm{~s}$; extension, 72 ${ }^{\circ} \mathrm{C} / 1.30 \mathrm{~min}$; and post-extension, $72{ }^{\circ} \mathrm{C} / 3 \mathrm{~min}$ ), and we designed specific primers to detect colonizing bacteria isolated from plant samples and thought to be $C$. taiwanensis KKU2500-3 (CD3-16S rDNAF; 5'GGGACCGCAAGGCCTCGCGC-3' and CD3-16S rDNAR; 5'-CTCCCCCTCGCGGGTTGGCAA-3'). The theoretical size of the product is $1,071 \mathrm{bp}$. The DNA fragments were visualized by gel electrophoretic analysis, and the sequence of the PCR product was aligned with the known sequence of $C$. taiwanensis KKU2500-3 16S rDNA. BLAST searches were performed using the NCBI database.

\section{Scanning electron microscopic (SEM) analysis}

Rice plants were collected at 28 DAT and double cleaned with sterile water. The samples were immersed in glutaraldehyde and paraformaldehyde in sodium cacodylate buffer $(\mathrm{pH} 7.2)$ at $28{ }^{\circ} \mathrm{C}$ for $2 \mathrm{~h}$ and cleaned 3 times with PBS ( $\mathrm{pH} 7.2$ ). Plant tissues were cut to detach the shoots and roots and soaked in osmium tetroxide in PBS at $4{ }^{\circ} \mathrm{C}$ for $2 \mathrm{~h}$, dehydrated in an ethanol series $(50-100 \%)$, and desiccated by critical point drying (modified from Mattos et al. [16]). Observations and micrographs were performed at the electron microscopic lab of the Biology Department of Khon Kaen University.

\section{Rice growth and yield determination}

Rice samples (3 plants/replicate, 3 replicates/treatment) from both treatments were randomly collected at 30 - 135 DAT to determine growth via biomass analysis, shoot and root length, and pigment content [7]. After transplanting every 15 days, rice leaves were cut into small pieces. Pigments were extracted with $80 \%$ acetone, and absorbance was measured by spectrophotometry at various wavelengths. The concentrations of chlorophyll $a$, chlorophyll $b$, and carotenoids were computed based on absorbance values [17]. Grain and components of rice yield were evaluated at the end of the experiment (135 DAT).

\section{Statistical analysis}

Data from each experiment were examined using analysis of variance (ANOVA), and the means (n $=3) \pm \mathrm{SD}$ were compared using an independent sample T-test. Significance was considered at $p \leq 0.05$ and $p \leq 0.01$. 
http://wjst.wu.ac.th

\section{Results and discussion}

\section{Activities of $C$. taiwanensis KKU2500-3 affecting rice growth and yield}

The growth curves showed that KKU2500-3 grew rapidly in NB medium for $6-18 \mathrm{~h}$ after the lag phase, while cells cultured in Burk's nitrogen-free medium grew slowly over a longer period of time (Figure 1A). This result demonstrated that this bacterium could grow under nitrogen-deficient conditions, suggesting that it has the ability to fix $\mathrm{N}_{2}$ from the atmosphere. In addition, strain KKU2500-3 was able to produce IAA and release it into NB medium at approximately $4 \mu \mathrm{g} \cdot \mathrm{mL}^{-1}$. The addition of $50-500$ $\mu \mathrm{M} \cdot \mathrm{mL}^{-1}$ of tryptophan to the medium promoted IAA production by KKU2500-3, especially when 300 $\mu \mathrm{M} \cdot \mathrm{mL}^{-1}$ tryptophan was used (Figure 1B). However, the strain was not able to produce more IAA when the concentration of tryptophan increased to $400-500 \mu \mathrm{M} \cdot \mathrm{mL}^{-1}$. The strain also exhibited the ability to solubilize $643.87 \mu \mathrm{g} \cdot \mathrm{mL}^{-1}$ insoluble phosphate in Pikovskaya's medium (Figure 1C). Although the bacterium showed many beneficial activities that resulted in enhanced plant growth, no siderophore production was observed.

(A)

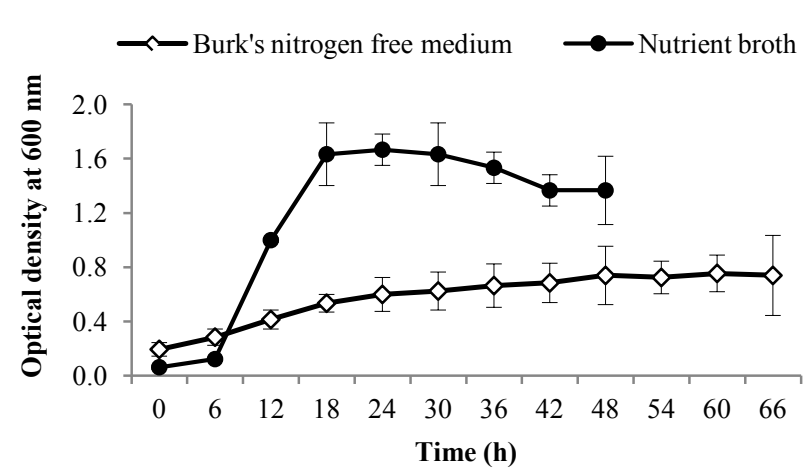

(B)

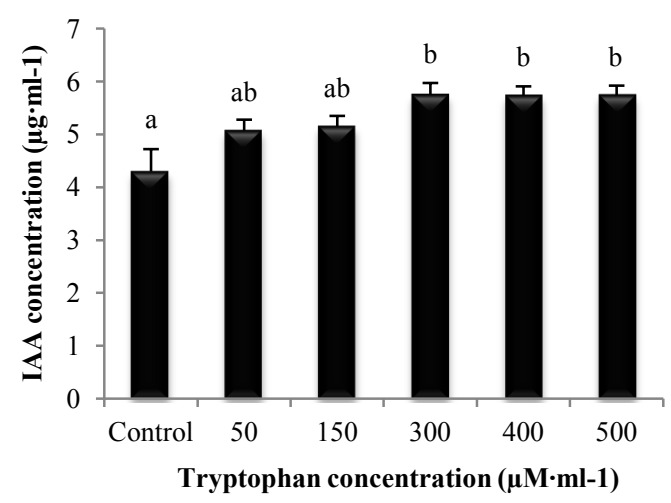

(C)

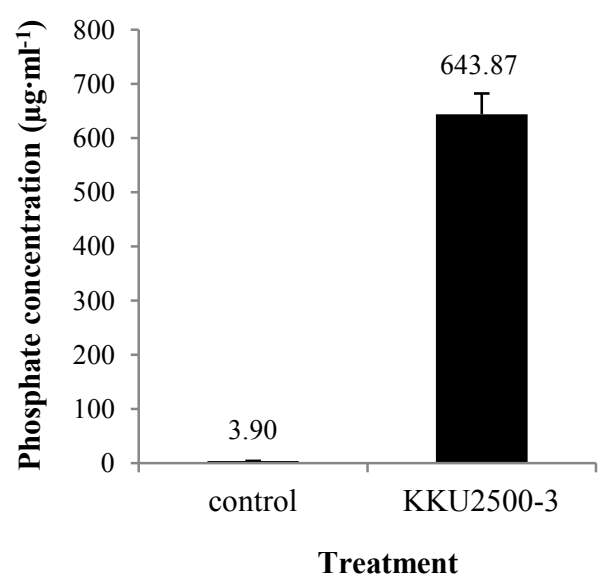

Figure 1 Plant growth-promoting abilities of C. taiwanensis KKU2500-3. (A) Growth of the bacterium in Burk's nitrogen-free medium compared with that in nutrient broth (NB), (B) IAA production with different concentrations of tryptophan, and (C) Phosphate solubilization in Pikovskaya's medium. 
http://wjst.wu.ac.th

\section{Rice plant growth under phosphate-free and enriched-phosphate conditions in Hoagland's agar \\ To determine the ability of KKU2500-3 to solubilize insoluble phosphate and make it available for} plants, rice seedling plants colonized with bacteria were grown on Hoagland's agar with or without insoluble calcium phosphate for days after transplantation. The results showed that shoot length and dry weight and root length and dry weight were similar between R and RB plants (Figure 2). However, the root dry weight of RB plants was higher that of $\mathrm{R}$ plants when no soluble phosphate was added (Figure 2B), indicating that the bacteria were able to solubilize insoluble phosphate to promote plant growth. At $100 \%$ soluble phosphate, the RB showed significant growth promotion compared to R plants, as assessed by root dry weight, possibly via other mechanisms besides phosphate solubilization of KKU2500-3.

(A)

$\mathrm{QR} \square \mathrm{RB}$

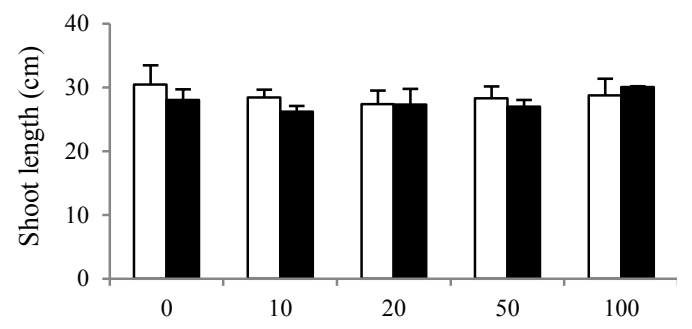

(\%) Soluble phosphate

(B)

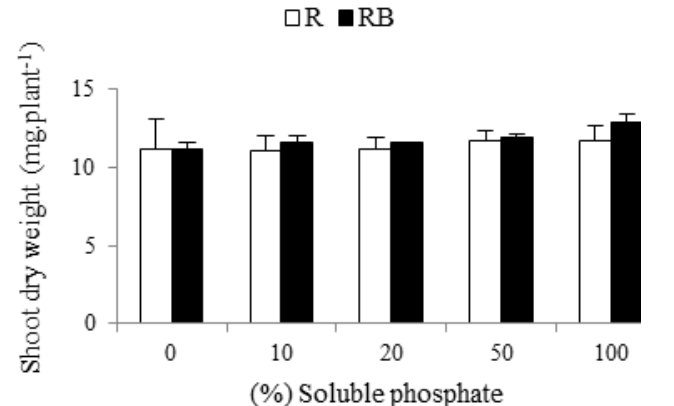

$\square \mathrm{R} \backsim \mathrm{RB}$

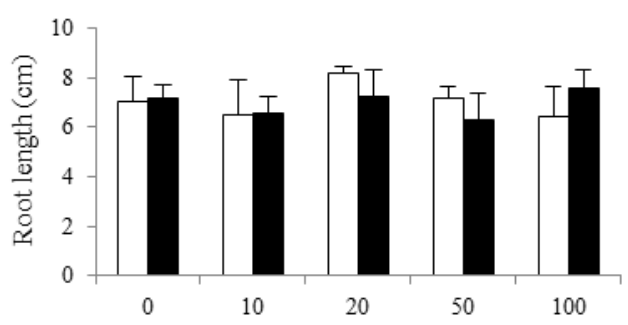

(\%) Soluble phosphate

$\mathrm{QR} \square \mathrm{RB}$

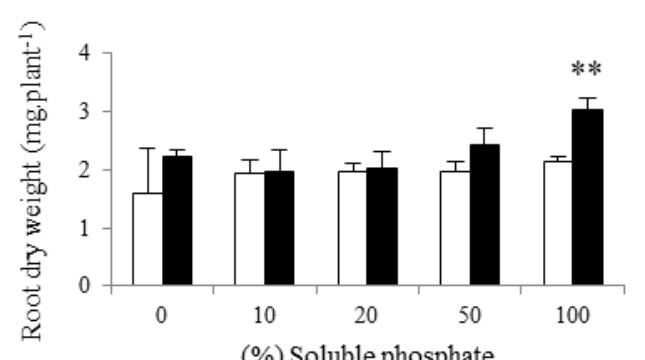

(\%) Soluble phosphate

Figure 2 Shoot and root lengths (A), shoot and root dry weight, (B) of KDML105 jasmine rice at 9 DAT growth in Hoagland's agar supplemented with soluble and insoluble phosphate without bacteria $(\mathrm{R})$ or inoculated with bacteria $(\mathrm{RB})$, means $\pm \mathrm{SD}, \mathrm{n}=3 . * *=$ significant difference at $p<0.01$ (t-test).

\section{Colonization of $C$. taiwanensis KKU2500-3 on KDML105 jasmine rice}

C. taiwanensis KKU2500-3 successfully colonized the root surfaces and migrated into roots and shoots from $30 \mathrm{DAT}$, ranging from 3 - $8 \mathrm{log} \mathrm{CFU} \cdot \mathrm{g}^{-1}$ plant (Figure 3). Throughout the experiment, the bacteria spread to different parts of the plant, with the highest numbers on the root surface, indicating that C. taiwanensis KKU2500-3 did not affect rice growth in Hoagland's solution. Agarose gel electrophoresis of the PCR products using DNA from all isolates revealed the same size as that of C. taiwanensis KKU2500-3 16S rDNA. The sequences of these PCR products show at least $97 \%$ similarity to the $16 \mathrm{~S}$ rDNA of other strains of $C$. taiwanensis, and $100 \%$ similarity to KKU2500-3. After root inoculation, 
http://wjst.wu.ac.th

SEM (Figure 4) showed colonization of the root surface by KKU2500-3 from observations of cell attachment and transfer into the roots, shoots, and leaves through the vascular bundle, enclosing cells within intercellular spaces.

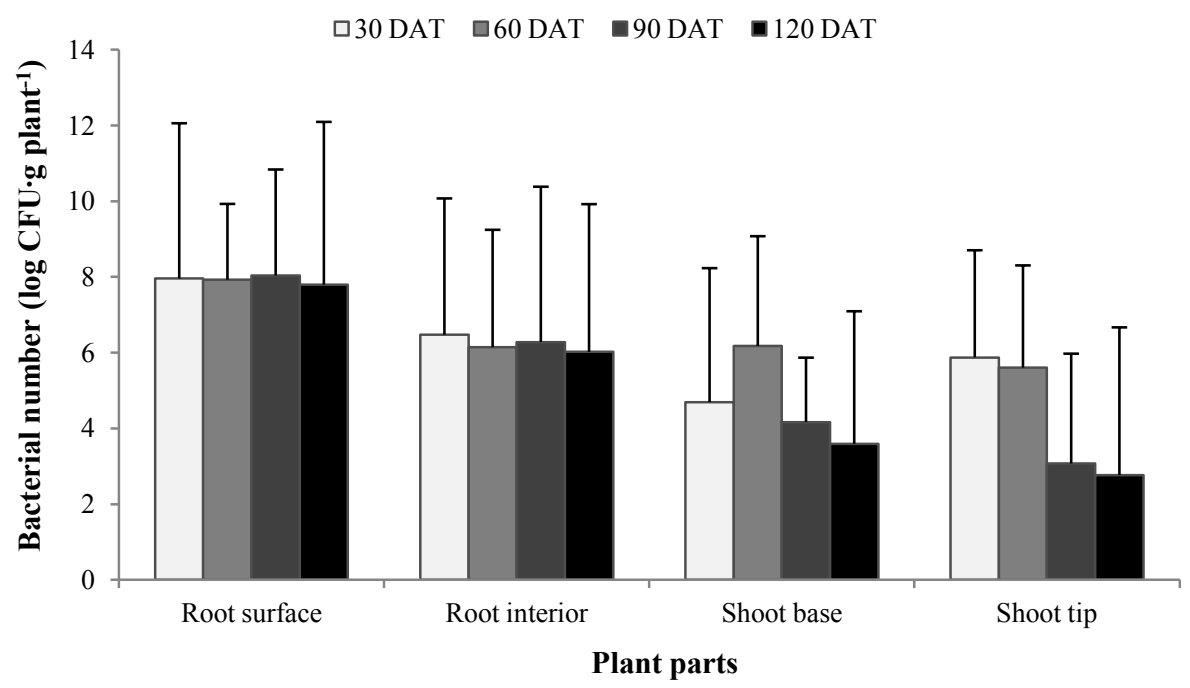

Figure 3 Number of cadmium-tolerant bacteria, likely to be C. taiwanensis KKU2500-3, isolated from rice plants at $30-120 \mathrm{DAT}$.

\section{Effects of $C$. taiwanensis KKU2500-3 on rice growth and pigment content}

The $\mathrm{R}$ rice plants (not inoculated with bacteria) showed continuous growth with timely increases in the length and biomass of the shoot and root from 30 - 135 DAT (Figure 5A). In contrast, the RB rice plants (colonized with bacteria) showed a longer root length than the control beginning at 45 DAT. Although the shoot lengths of the rice plants in each treatment were similar, their dry weights were significantly different, especially at 120 - 135 DAT (Figure 5B). A pigment content analysis demonstrated that the bacteria dramatically increased the chlorophyll $a$ and $b$ contents of the RB rice plants. The chlorophyll content between the 2 treatments was markedly dissimilar at 75 DAT, whereas carotenoid levels were similar (Figure 5C). The overall morphology of non-inoculated and inoculated rice plants showed that C. taiwanensis KKU2500-3 promotes root hair formation (Figure 6) in young plants, and the RB rice plants appeared healthier than the R rice plants (Figures 6 and 7).

\section{Effects of $C$. taiwanensis KKU2500-3 on rice yield}

At 135 DAT, rice yield components and grain yield, including the panicle length and number of seeds/panicle, were determined. The KKU2500-3 strain altered the panicle length, number of filled grains/panicle, filled grain percentage and, most notably, the 100-grain weight (Table 1). Although the number of seeds/panicle was not significantly different between the treatments, the filled grain yield for the $\mathrm{RB}$ plants was greater than that of the $\mathrm{R}$ plants. The most important results were the significant differences in the number of filled grains/panicle and the grain mass of the rice plants inoculated with the bacteria, with both parameters demonstrating that both the quality and quantity of the total product was higher than that of the control plants. 

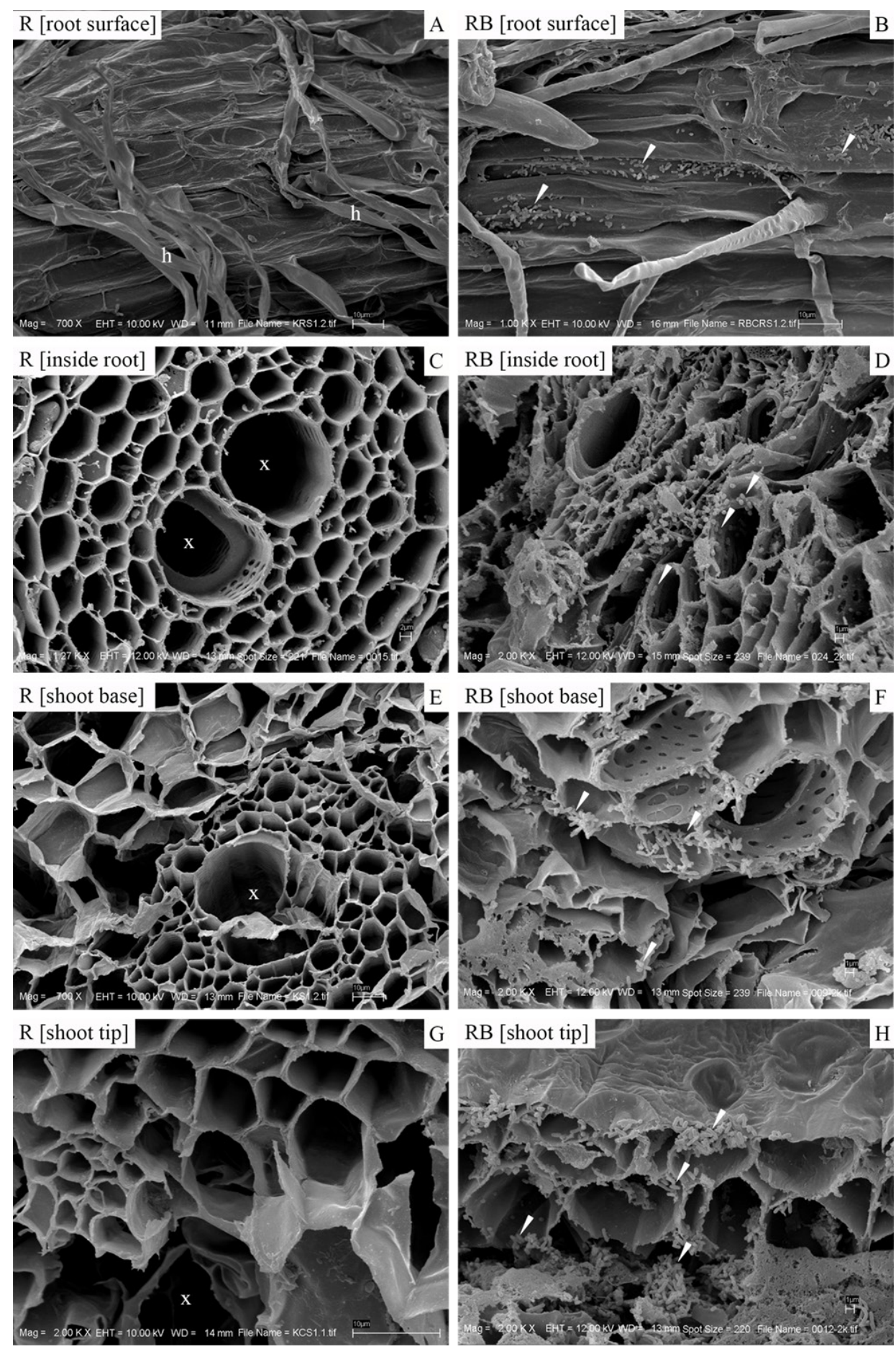

Figure 4 Electron micrographs of bacteria (arrows), which are likely C. taiwanensis KKU2500-3, colonizing the root surface, the root interior, the shoot base, and the shoot tip of KDML105 rice in control plants (R; shown in A, C, E, G) and bacterium-inoculated plants (RB; shown in B, D, F, H) when grown in Hoagland's solution for 28 days, $\mathrm{h}=$ root hair, $\mathrm{x}=\mathrm{xylem}$. 
http://wjst.wu.ac.th

(A)

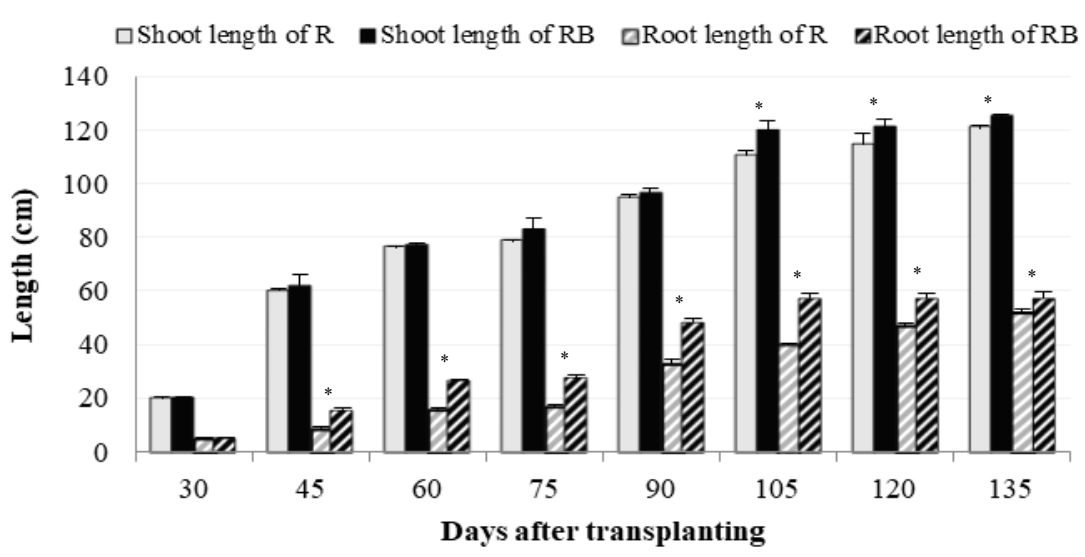

(B)

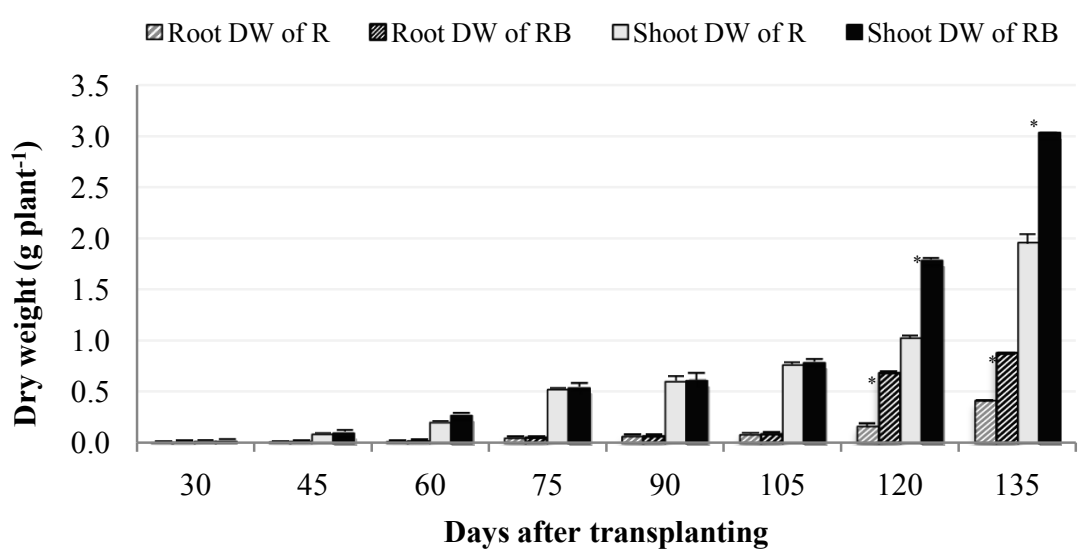

(C)

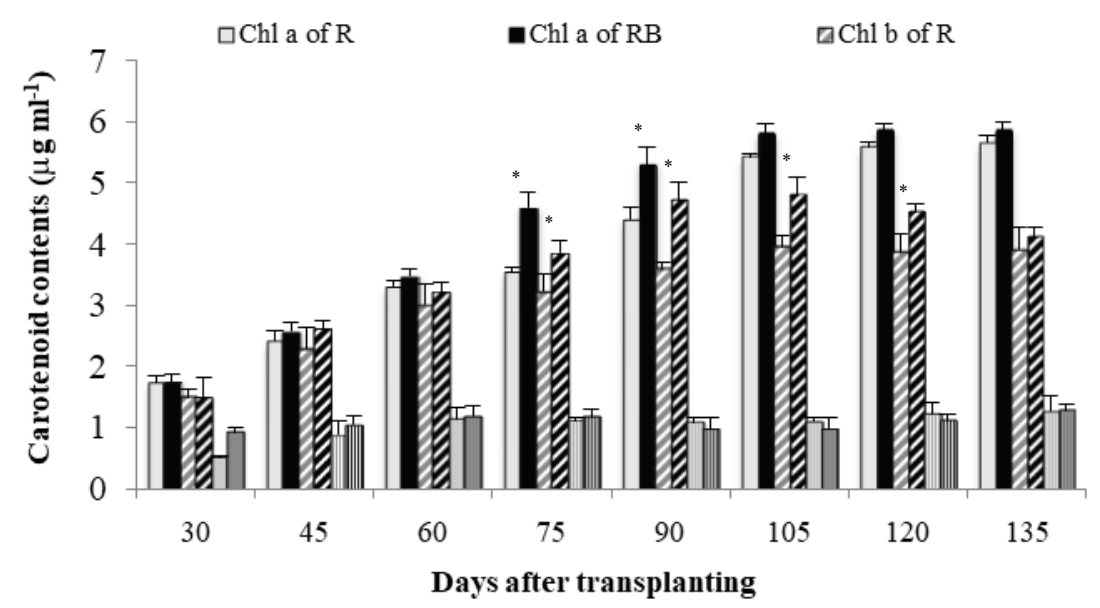

Figure 5 Shoot and root lengths (A), shoot and root dry weights (B), and pigment contents (C) of KDML jasmine rice plants at $30-135$ DAT in hydroponic systems without bacteria $(\mathrm{R})$ and inoculated with bacteria $(\mathrm{RB} ;$ means $\pm \mathrm{SD}, \mathrm{n}=3)$. $\mathrm{ns}=$ no significant difference, ${ }^{*}=$ significant difference at $p<0.05(\mathrm{~T}-$ test). 

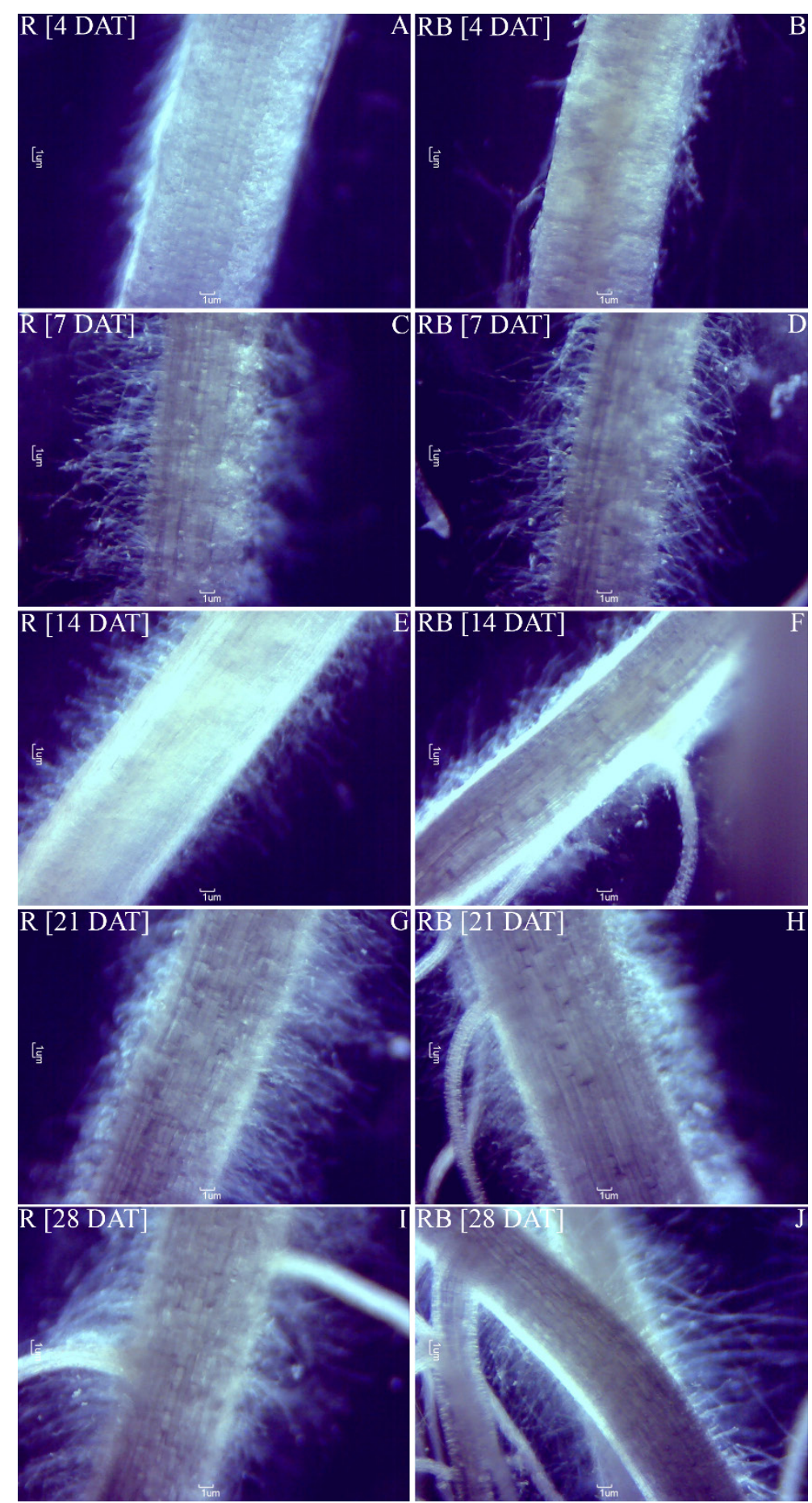

Figure 6 Light micrographs of KDML 105 rice seedling roots at 4, 7, 14, 21, and 28 DAT in hydroponic systems without bacteria (R; shown in A, C, E, G, I) or inoculated with bacteria (RB; shown in B, D, F, H, J). 
http://wjst.wu.ac.th

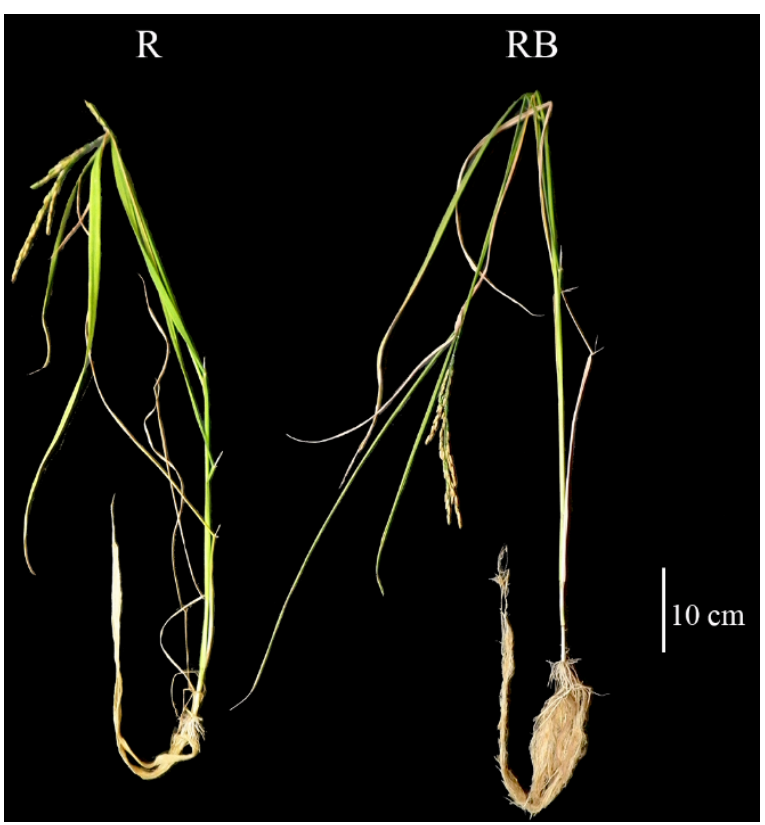

Figure 7 Rice plant characteristics at 135 DAT of growth in hydroponic systems without bacteria $(\mathrm{R})$ or inoculated with bacteria (RB).

Table 1 Yield parameters and grain yield (means $\pm \mathrm{SD}, \mathrm{n}=3$ ) of rice at $135 \mathrm{DAT}$.

\begin{tabular}{cccccc}
\hline Treatment & $\begin{array}{c}\text { Panicle } \\
\text { length }(\mathbf{c m})\end{array}$ & $\begin{array}{c}\text { No. of seeds/ } \\
\text { panicle }\end{array}$ & $\begin{array}{c}\text { No. of filled } \\
\text { grains/panicle }\end{array}$ & $\begin{array}{c}\text { Filled grain } \\
\text { percentage }\end{array}$ & $\begin{array}{c}\text { 100 grain weight } \\
(\mathbf{g})\end{array}$ \\
\hline $\mathrm{R}$ & $20.5 \pm 1.1$ & $53.2 \pm 8.3$ & $33.9 \pm 5.9$ & $63.7 \pm 6.2$ & $1.8981 \pm 0.0882$ \\
$\mathrm{RB}$ & $23.3 \pm 1.0$ & $59.6 \pm 3.0$ & $50.2 \pm 1.4$ & $84.5 \pm 4.8$ & $2.3446 \pm 0.0395$ \\
\hline T-test & $*$ & $\mathrm{~ns}$ & $*$ & $*$ & $*$ \\
\hline
\end{tabular}

T-test $(\mathrm{n}=3), \mathrm{ns}=$ non-significant difference, $*$ = significant difference $(p<0.05)$

\section{Discussion}

The results of this study demonstrate that the growth and yield of KDML105 jasmine rice plants was significantly increased by colonization of $C$. taiwanensis KKU2500-3. The observed differences between non-colonized and colonized rice plants indicated that this bacterial strain enhanced the growth of rice plants with respect to several characteristics (Figure 5). At 45 DAT, the root length and shoot dry mass were greater in $\mathrm{RB}$ rice plants than in $\mathrm{R}$ rice plants. However, the longer roots of $\mathrm{RB}$ rice plants did not exhibit increased dry weight at that time, although they increased notably at 120 DAT until the ripening stage. As roots are important plant structures implicated in the acquisition of water and minerals, production of some hormones, anchoring of plants, and interactions with soil bacteria [18,19], their structures and functions are intimately related to the growth and development of the aerial parts of plants.

Possible explanations for the observed interactions include the following.

(i) The IAA produced by the bacteria enhanced root growth and development by encouraging root elongation, lateral root formation, and mineral accumulation, as reflected in the growth of plant shoots $[20,21]$. Consistent with our previous observations, KKU2500-3 can produce IAA and, thus, improve lateral root production [5]. Auxins are widely used in tissue culture to enhance initiation of new root 
http://wjst.wu.ac.th

primordia and stimulate root elongation. New root formation is initiated by relatively high levels, whereas root elongation is motivated by lower doses. Corresponding to our findings, Yang et al. [22] also reported that a high root biomass and high levels of other plant hormones, such as abscisic acid (ABA) and cytokinin, are needed for high grain-filling rates, grain-filling percentages, and grain yields. These requirements may be the result of spreading of the colonized bacteria from the root to the shoot of KDML105 rice. Inoculation with KKU2500-3 markedly increased root growth in young plants by promoting root elongation and lateral root formation (Figure 6) and in mature plants by enhancing root biomass accumulation (Figure 5), allowing plants to access more nutrients and water. This result is interesting because the morphological modifications induced by these bacteria were beneficial. Thus, colonization and activities of such bacteria likely affect plant growth and development.

(ii) The root exudate tryptophan is a substrate in the IAA biosynthetic pathways of rhizosphere bacteria, and an important component of bacterial IAA is then distributed to the root [23]. As demonstrated by our study, exogenous tryptophan improved IAA production by strain KKU2500-3, confirming the symbiotic relationship between KDML105 jasmine rice and the bacteria. In addition to tryptophan, other precursors, such as root-secreted pyruvate, can enter IAA production through several biosynthetic pathways [24]. Whether the KKU2500-3 strain enhanced IAA production in colonized rice plants remains to be elucidated.

(iii) The ability to convert atmospheric nitrogen to ammonium $\left(\mathrm{NH}_{4}^{+}\right)$is one of the strongest effects of KKU2500-3 in enhancing rice growth and yield. The ability to fix nitrogen is widespread among plantpromoting rhizobacteria, including many rhizobia and C. taiwanensis strains $[25,26]$. An important factor in this reaction is the enzyme nitrogenase [27,28]. Although the application of nitrogen fertilizer is central to high-yield rice production, the mass, length, and surface area of the root also increased with increasing nitrogen [29]. Moreover, biological nitrogen fixation by microorganisms is a very important nitrogen source for rice plants [30]. In this study, although we found that C. taiwanensis KKU2500-3 affected plant growth, the impact may depend on the application method, dose, and timing [31].

(iv) According to our results, C. taiwanensis KKU2500-3 can be used as a biofertilizer, as this strain can produce phytohormones such as IAA, fix nitrogen, and solubilize insoluble phosphate. Interestingly, the ability of KKU2500-3 to reduce cadmium accumulation in rice seedlings [5] makes it a promising strain for further investigations of the production of low-cadmium-accumulating rice plants grown in contaminated rice fields.

\section{Conclusions}

Colonization of KDML105 jasmine rice plants by C. taiwanensis KKU2500-3 enhanced the growth and increased plant dry matter and chlorophyll contents, as well as the quality and quantity of rice yield. These improvements led to noteworthy increases in grain yield with regard to both number and weight, with a value 48.20 and $23.53 \%$ greater than that of the control, respectively. All plant growth and yield results were due to a combination of bacterial activities, including nitrogen fixation, IAA production, and phosphate solubilization.

\section{Acknowledgments}

This work was supported by grants from the Higher Education Research Promotion and National Research University Project of Thailand, Office of the Higher Education Commission (Grant number W2553-Ph.D-08), through the Holistic Watershed Management Cluster of Khon Kaen University, from the National Science and Technology Development Agency of Thailand (Grant number P-09-00853), and from Khon Kaen University Under Incubation Researcher Project, and was partly funded by the National Research Council of Thailand. 
http://wjst.wu.ac.th

\section{References}

[1] F Ahmad, I Ahmad, MS Khan. Screening of free-living rhizospheric bacteria for their multiple plant growth promoting activities. Microbiol. Res. 2008; 163, 173-81.

[2] C Contesto, S Milesi, S Mantelin, A Zancarini, G Desbrosses, F Varoquaux, C Bellini, M Kowalczyk and B Touraine. The auxin-signaling pathway is required for the lateral root response of Arabidopsis to the rhizobacterium Phyllobacterium brassicacearum. Planta 2010; 232, 1455-70.

[3] WM Chen, S Laevens, TM Lee, T Coenye, PD Vos, M Mergeay and P Vandamme. Ralstonia taiwanensis sp. nov., isolated from root nodules of Mimosa species and sputum of a cystic fibrosis patient. Int. J. Syst. Evol. Microbiol. 2001; 51, 1729-35.

[4] WM Chen, L Moulin, C Bontemps, P Vandamme, G Béna and C Boivin-Masson. Legume symbiotic nitrogen fixation by beta-proteobacteria is widespread in nature. J. Bacteriol. 2003; 185, 7266-72.

[5] S Siripornadulsil and W Siripornadulsil. Cadmium-tolerant bacteria reduce the uptake of cadmium in rice: potential for microbial bioremediation. Ecotoxicol. Environ. Saf. 2013; 94, 94-103.

[6] P Punjee, W Siripornadulsil and S Siripornadulsil. Effects of cadmium-resistant bacteria, Cupriavidus taiwanensis KKU2500-3, on Thai jasmine rice to cadmium toxicity. Curr. Opin. Biotech. 2013; 24, S28-S47.

[7] P Punjee. 2016, Effects of Cadmium-resistant Bacteria on Rice Plant Growth and Its Cadmium Accumulation. Ph. D. Thesis, Khon Kaen University, Khon Kaen, Thailand.

[8] JC Cappuccino and N Sherman. Negative Staining. In: JC Cappuccino and N Sherman (Eds.). Microbiology: A Laboratory Manual. $3^{\text {rd }}$ eds. Benjamin/Cummings, Redwood City, 1992, p. 12579.

[9] JM Bric, RM Bostock and SE Silverstone. Rapid in situ assay for indole acetic acid production by bacteria immobilized on a nitrocellulose membrane. Appl. Environ. Microbiol. 1991; 57, 535-8.

[10] B Schwyn and JB Neilands. Universal chemical assay for the detection and determination of siderophores. Anal. Biochem. 1987; 160, 47-56.

[11] RI Pikovskaya. Mobilization of phosphorus in soils in connection with vital activity of some microbial species. Mikrobiologiya 1948; 17, 362-70.

[12] AH Goldstein. Bacterial solubilization of mineral phosphates: Historical perspective and future prospects. Am. J. Alter. Agr. 1986; 1, 51-7.

[13] EJ King. The colorimetric determination of phosphorus. Biochem. J. 1932; 26, 292-7.

[14] EK James, P Gyaneshwar, N Mathan, WL Barraquio, PM Reddy, PP Iannetta, FL Olivares and JK Ladha. Infection and colonization of rice seedlings by the plant growth-promoting bacterium Herbaspirillum seropedicae Z67. Mol. Plant Microbe Interact. 2002; 15, 894-906.

[15] DR Hoagland and DI Arnon. The water-culture method for growing plants without soil, Circular. Calif. Agr. Exp. Stat. 1950; 347, 1-32.

[16] KA Mattos, VL Pádua, A Romeiro, LF Hallack, BC Neves, TM Ulisses, CF Barros, AR Todeschini, JO Previato and L Mendonça-Previato. Endophytic colonization of rice (Oryza sativa L.) by the diazotrophic bacterium Burkholderia kururiensis and its ability to enhance plant growth. An. Acad. Bras. Cienc. 2008; 80, 477-93.

[17] HK Lichtenthaler and C Buschmann. Chlorophylls and Carotenoids: Measurement and Characterization by UV-vis Spectroscopy. In: HK Lichtenthaler and C Buschmann. (Eds.). Current Protocols in Food Analytical Chemistry. John Wiley \& Sons, New York, 2001, p. 24-56.

[18] S Yao, S Taketa and M Ichii. A novel short-root gene that affects specifically early root development in rice (Oryza sativa L.). Plant Sci. 2002; 163, 207-15.

[19] C Yang, L Yang, Y Yang and Z Ouyang. Rice root growth and nutrient uptake as influenced by organic manure in continuously and alternately flooded paddy soils. Agr. Water Manag. 2004; 70, 67-81.

[20] B Lippmann, V Leinhos and H Bergmann. Influence of auxin producing rhizobacteria on root morphology and nutrient accumulation of crops. I: Changes in root morphology and nutrient 
http://wjst.wu.ac.th

accumulation in maize caused by inoculation with indole-3-acetic acid producing Pseudomonas and Acinetobacter strains or IAA applied exogenously. Angew. Bot. 1995; 69, 31-6.

[21] DP Sachdev, HG Chaudhari, VM Kasture, DD Dhavale and BA Chopade. Isolation and characterization of indole acetic acid (IAA) producing Klebsiella pneumoniae strains from rhizosphere of wheat (Triticum aestivum) and their effect on plant growth. Indian J. Exp. Biol. 2009; 47, 993-1000.

[22] J Yang, H Zhang and J Zhang. Root morphology and physiology in relation to the yield formation of rice. J. Integr. Agr. 2012; 11, 920-6.

[23] S Spaepen, J Vanderleyden and R Remans. Indole-3-acetic acid in microbial and microorganismplant signaling. FEMS Microbiol. Rev. 2007; 31, 425-48.

[24] M Bacilio-Jiménez, S Aguilar-Flores, E Ventura-Zapata, E Pérez-Campos, S Bouquelet and E Zenteno. Chemical characterization of root exudates from rice (Oryza sativa) and their effects on the chemotactic response of endophytic bacteria. Plant Soil 2003; 249, 271-7.

[25] M Marchetti, O Catrice, J Batut and C Masson-Boivin. Cupriavidus taiwanensis bacteroids in mimosa pudica indeterminate nodules are not terminally differentiated. Appl. Environ. Microbiol. 2011; 77, 2161-4.

[26] A Klonowska, C Chaintreuil, P Tisseyre, L Miché, R Melkonian, M Ducousso, G Laguerre, B Brunel and L Moulin. Biodiversity of mimosa pudica rhizobial symbionts (Cupriavidus taiwanensis, rhizobium mesoamericanum) in New Caledonia and their adaptation to heavy metal-rich soils. FEMS Microbiol. Ecol. 2012; 81, 618-35.

[27] M Stella and M Suhaimi. Selection of suitable growth medium for free-living diazotrophs isolated from compost. J. Trop. Agr. Food Sci. 2010; 38, 211-9.

[28] B Lugtenberg, N Malfanova, F Kamilova and G Berg. Plant Growth Promotion by Microbes. In: FJ de Bruijn (Ed.). Molecular Microbial Ecology of the Rhizosphere, Wiley Blackwell, Hoboken, NJ, 2013, p. 561-73.

[29] J Fan, Y Zhang, D Turner, Y Duan, D Wang and Q Shen. Root physiological and morphological characteristics of two rice cultivars with different nitrogen-use efficiency. Pedosphere 2010; 20, 446-55.

[30] BB Bohlool, JK Ladha, DP Garrity and T George. Biological nitrogen fixation for sustainable agriculture: A perspective. Plant Soil 1992; 141, 1-11.

[31] KR Reddy and WHJ Patrick. Yield and nitrogen utilization by rice as affected by method and time of application of labelled nitrogen. Agron. J. 1976; 68, 965-9. 